\title{
Governing Ignorance: Emerging Catastrophic Risks- Industry Responses and Policy Frictions
}

\section{Giuliano Castellano}

Pole de Recherche en Gestion (PREG), Ecole Polytechnique and International University College of Turin, PREG-CRG/ENSTA, 32 Boulevard Victor, PARIS Cedex 15 75739, France.

E-mail: giuliano.castellano@polytechnique.edu

The growing interconnections between people, markets and networks together with the development of new technologies have increased the frequency and impact of large-scale disasters around the globe. Many of these events, defined as emerging catastrophic (or systemic) risks, have no previous record. At the same time there is a strong probability that their frequency and impact will increase in the future. This paper takes a governance perspective by assuming that policy actions should be designed to cope with ignorance and large-scale losses, being the primary features characterising such emerging catastrophic risks. Precisely, the governance activity should aim both at expanding the industries' capacity to absorb losses and at acquiring more information about frequency and impact of such losses. However, it appears that some solutions may conflict with policy objectives. In particular, direct governmental interventions to compensate victims and stringent antitrust policy goals might block the development of a market for first-party property insurance for emerging systemic risks. This paper elicits crucial points that require further elaboration by policy-makers, thereby stressing the importance of providing a workable legal definition of such line of risk that embraces the precautionary principle.

The Geneva Papers (2010) 35, 391-415. doi:10.1057/gpp.2010.11

Keywords: emerging catastrophic risks; new risks; pooling; precautionary principle; antitrust; Block Exemption Regulation

\section{Introduction}

New forms of catastrophic events, usually defined as emerging catastrophic (or systemic) risks, have gained increasing attention at the international level, as the occurrences of such losses have increased and policy actions are required to minimise future losses caused by unexpected large-scale damages. ${ }^{1}$ Typically this category of risks is related to the implementation of new technologies (such as genetic engineering), the collapse of critical infrastructures, the unpredictable effects of climate changes or Global Geophysical Events. At a first glance it might appear that this line of risk partially corresponds to the traditional natural or man-made catastrophic events; however, emerging catastrophic risks are characterised by a higher level of unpredictability and thus require specific governance actions.

\footnotetext{
${ }^{1}$ OECD (2003).
} 
Precisely because of the "ignorance" - defined here as the lack of previous recordsof such occurrences the high losses associated with them can hardly be avoided. Moreover, their dimensions impose a displacement of a massive amount of financial resources that might easily exceed insurers' reserves as well as public budgets, as the recent earthquake in Haiti has demonstrated. ${ }^{2}$ A policy action appears to be required in order to tackle these risks. However, when business practices or, more generally, governance techniques enter in conflict with other primary policy goals, a solution appears to be much more far to be reached.

This paper looks at this particular problem from a holistic perspective in an attempt to outline possible policy actions that can ultimately lead to a consistent governance approach. Moving from the experiences of other categories of peak-risks, the "Introduction" section of this paper analyses the core features of emerging catastrophic risks, in order to find a definition of such a line of risk, which represents a fundamental prerequisite for any policy actions or business choices. By drawing some lessons from the insurability of catastrophic losses, the section "Anatomy of ignorance: policy perspective and industry responses" takes a governance perspective and illustrates why a specific action has to be adopted in order to expand the industry's capacity and to gather sufficient information about such occurrences. Since certain business practices might conflict with other relevant policy goals, the section "Conflicting goals: a policy perspective" examines, by way of factual examples, different policy frictions that might arise when a direct governmental (ex post) intervention is adopted or when an ex ante arrangement, such as the mandatory catastrophe extension of first-party property insurance, is put in place. The section "Competition law concerns and the definition of new risks" analyses the Italian case, where the antitrust authority rejected two different bills aiming at creating a mandatory catastrophe extension of first-party property coupled by a consortium mechanism. It also examines the benefits of having risk pooling for emerging risks, as acknowledged by the EU Commission case law that lead to the enactment of the Block Exemption Regulation, which has been renewed for another seven years. Further, it looks at the definition of "new risks" embedded in the current Regulation, which is likely to be modified in the new proposal. These definitions appear to be particularly stringent and not suitable for the enactment of a risk-based governance approach.

\section{Emerging catastrophic risks: dealing with large-scale, unpredictable events}

At the beginning of his famous book $^{3}$ dealing with cataclysms, Richard Posner describes a series of catastrophic events - ranging from asteroid strikes to bioterrorist attacks - that might lead to unpredictable, though devastating, consequences. Such circumstances are often included within the broader family of extreme events or peak

\footnotetext{
${ }^{2}$ The World Bank estimates the costs suffered of at least 15 per cent of the country's GDP. This estimation is still approximate and based on the data concerning the last four tropical storms hitting the country in 2008.

${ }^{3}$ Posner (2004).
} 
risks. This definition, however, includes not only the apocalyptic scenarios described in the introductory pages of Judge Posner's book, but also those events characterised by a low probability/high damage ratio.

Leaving aside (from the scope of this work) those events that will determine the extinction of our civilisation - which eventually resolves any speculation over optimal compensatory mechanisms - it appears that these risks are strongly diverse in nature, and that they have no previous records. ${ }^{4}$ Accordingly, unpredictable events-like an infrastructure failure such as a blackout (e.g. the 1999 Southern Brazil Blackout or the Northeast Blackout of 2003 that occurred in the United States and Canada), a largescale financial crisis with deep consequences in the real economy (e.g. the Icelandic financial crisis), a non-conventional terrorist attack, or the risk related with the exploitation of new technologies - may suddenly cause huge amounts of loss.

Even if, by definition, a clear identification of this risk line cannot be conceived, as ignorance is one of the core elements characterising such events, insurers consider emerging risks as risks that, although poorly known, are expected to grow steadily in their significance. In other words, there are a number of occurrences that we are simply not able to estimate in advance. Of course, not all of them should be directly insured or even be a concern. Nevertheless, it appears that there are some unexpected (and unprecedented) extreme events increasing both in their overall frequency and in their negative impact.

\section{The boundaries of emergent risks: the precautionary principle}

In support of the quest for a workable definition of emergent catastrophic risks the precautionary principle can be adopted, which holds that a preventive measure should be taken every time there is a danger (even if not fully estimated) of damages. In other words, where there are threats of serious or irreversible damage, the lack of full scientific certitude about whether the harm could arise should not impede the application of cost-effective preventive measures.

In international law this principle applies to environmental protection and it is stated in a number of international conventions, and in the EC Treaty. ${ }^{5}$ Here it is useful to recall it in order to understand up to what point emerging risks have to be a concern and thus determine a prompt action. An answer to this question can only be provided on a case-by-case basis - that is after fully estimating costs and benefits of an extensive prevention activity. ${ }^{6}$ As distinguished scholars have pointed out, an excessive use of precautionary measures might lead to the bearing of higher costs than those caused by the damage prevented. ${ }^{7}$

\footnotetext{
${ }^{4}$ For instance, a gigantic asteroid strike (and the subsequent abrupt climate changes) appears to be the cause of the dinosaurs' extinction; the frequency of such an event (during the existence of human beings) is very low.

${ }^{5}$ For instance in the Stockholm Convention of 1972 and in the Rio Convention of 1992. The EC Treaty at Article 174 (2) states such principle in defining the EC environmental policy.

${ }^{6}$ Faure and Skogh (2003).

${ }^{7}$ Baker (2002). See also Baker and Simon (2002).
} 
Nevertheless, even if it is often considered a vague concept, the precautionary principle shifts the burden of proof from those advocating precautions to those opposing it. ${ }^{8}$ This turns out to be a useful aspect to single out a heuristic definition of emerging catastrophic risks, as in the circumstances in which reasonable scientific grounds for believing that a new risk is foreseen, preventive measures should be introduced until there is convincing evidence that the threat is small and is outweighed by the benefits of not having over-prevention. As a consequence, not all emerging risks can be considered as threats that have to be prevented, but only those risks for which an increase in significance is reasonably expected and the risk of future losses are high.

For a number of reasons it appears that the intensity of different catastrophic events is growing; this is proven by the fact that all of the 20 most costly insured catastrophes registered over a 38 year period (1970-2007), have occurred after 1987, and half of them occurred after 2001. ${ }^{9}$ Even more, a series of other risks, about which there is little historical record on as to their impact on the population (though there is reasonable probability that they might have a highly negative impact), can be enumerated: genetically modified organisms in the food chain, ${ }^{10}$ Global Geophysical Events (e.g. super-volcanoes, giant tsunamis or unexpected near earth objects), critical infrastructure risks - which is the risk that critical infrastructure whose incapacity or destruction would destabilise the society, menacing security (such as communications, electrical power systems, gas and oil, banking and finance, water supply and transportations just to mention some of them).

Such an increase in the frequency and in the impact of large-scale damages is mainly due to the growing interconnection between people, the increase of the population, global warming and technological development. Pandemic diseases that occurred during the last centuries were more localised; although nowadays, due to the frequency of overseas travelling, infections might easily become a global threat.

A similar point could be made for financial crises: "Since 1973 crisis frequency has been double that of the Bretton Woods and classical gold standard periods and matched only by the crisis-ridden 1920s and 1930s." 11 Owing to the strong linkage among financial institutions and markets, the failure of a bank might easily cause the failure of other healthy credit institutions by activating a chain reaction that will dramatically affect the real economy. Practitioners and policy-makers properly define such a domino mechanism as contagion.

The diverse scenario just illustrated here might be exacerbated by other actual threats. Emerging catastrophic occurrences might be generated unconsciously by a repeated behaviour that, after some years, appears to cause damages. As scientific research progresses, it might reveal that some of the products we regularly use in our everyday lives actually cause long-term health problems, such as, for instance, electromagnetic waves. ${ }^{12}$

\footnotetext{
${ }^{8}$ Skipper and Kwon (2007).

${ }^{9}$ Michel-Kerjan and Kunreuther (2008).

${ }^{10}$ Tests to date are not yet able to prove damages, nevertheless the risks and the cost-benefits assessment (under the precautionary principle) might profoundly change if the social, cultural, environmental and political arguments are plugged into the equation.

${ }^{11}$ Bordo et al. (2001, pp. 53-82).

${ }^{12}$ Tom Baker (2002) explains how our efforts to prevent losses tend to generate other, unexpected losses by
} 
Such occurrences are often classified as development risks, corresponding to those damages generated by a product, whose harmfulness was not foreseeable at the time it was built or designed. ${ }^{13}$

These examples are helpful to identify the core elements of such emerging occurrences and the urgency for a governance action to tackle the massive costs, as it appears that nowadays unexpected losses are more likely to spread across the world very rapidly. In this sense, in line with the precautionary principle - without the risk of incurring in over-prevention - the scope of action appears more defined.

\section{Core features: drawing a line of action}

From the above, and from the examples provided, it is possible to outline the fundamental features embedded in the emerging catastrophic risk category. Those characteristics can be summarised as follows:

(a) unexpected and/or unforeseeable;

(b) high and cumulated losses;

(c) increasing occurrence; and

(d) ignorance.

The last feature, ignorance, appears particularly relevant to define emerging risks and to distinguish them from the natural or man-made cataclysms. A lack of knowledge about the events determines the unpredictability of a given occurrence and its impact, which can be shared with other peak risks. For instance, we know that some catastrophic events (such as earthquakes) are likely to occur in a given region; nevertheless we are not able to predict the lapse of time in which such events will occur, the population affected, nor its consequences.

However, where emerging risks are concerned, the general unpredictability over the events increases and assumes the traits of "ignorance", as even if it is recognised that there is a likely probability that a large-scale loss will occur, there are no sufficient previous records to provide insurance coverage nor to prepare an effective compensation scheme. The vast impact of these occurrences calls for an a priori and clearly defined policy response to: (i) minimise (if possible) the risk occurrence (and/or its impact); (ii) manage the event; and (iii) compensate victims. The resources necessary are massive and they mainly come from public funds, which, in the worst scenario, might not be sufficient for the poorest countries but also for European countries. ${ }^{14}$ Insurers, on the other hand, often claim the uninsurability of extreme or uncertain

giving an example of the threat created by asbestos, once considered as a tool to prevent harm (see also Baker and Simon, 2002).

${ }^{13}$ See, in general, Taylor (1999); see Fairgrieve and Howells (2007) over the EU Directive and over development defence.

14 To provide a significant figure of the economic risks related to such risks, let us consider, for instance, the overall economic value at risk in the buildings constructed within 500 metres of the European coastline. The value is estimated to be approximately between 500 and 1000 billion Euros (see Water Information System Europe, 2008). On the other hand, the population living in this geographical area is expected to rise from 2.3 to 3.6 million in the next 20 years (see Crichton, 2008). 
events. Nevertheless, some efforts in insuring the uninsurable have been made by creating room for a profitable market for catastrophic insurance (see the section "Anatomy of ignorance: policy perspective and industry responses"). Of course, particularly for emerging risks, the private sector might face several difficulties in managing such circumstances, which are generally referred to as uninsurable.

As the technology to forecast future events is progressing and the techniques to manage uncertainty are becoming more sophisticated, some possible solutions ensuring economic relief to victims should be defined. However, the road towards such a goal has to pass through a public and private common action, particularly by eliminating those legal arrangements that might set narrow boundaries on private action. By focusing on the European context, a number of lessons can be learned from the measures taken to cope with catastrophic events and several issues might be highlighted in order to draw a feasible solution involving the private insurance industry.

\section{Anatomy of ignorance: policy perspective and industry responses}

Having elicited the core characteristics of such emerging occurrences and identified the line of risk, it is worth asking: What are the governance issues embedded in such a line of risk? Can we learn any lessons from other categories? Although emerging risks, as characterised by lack of knowledge as to their frequency and impact, cannot be fully estimated, from the above discussion it appears that peak-risk scenarios present many similarities with catastrophic events. ${ }^{15}$ An analysis of this line of risk is worth conducting for the distinction between disasters and emerging risks appears to be blurred in many circumstances. In fact, many natural or man-made disasters - because they have manifested themselves in recent times only-are in some circumstance-considered emerging risks. In this sense, several lessons can be learned from the approaches adopted to cope with extreme events.

\section{Governance techniques}

By acquiring a broader perspective, it appears that emerging risks pose specific problems in terms of governance and policy approaches. In sociological terms, it is important to discern between disciplinary and risk-based governance. The former is characterised by normalising institutions and it is organised around five steps: (i) establishing an ideal norm; (ii) observation of individual cases; (iii) comparison between the ideal norm and the individual to isolate the problem; (iv) ensure individual compliance; (v) analyse the evidence from all the individual cases in order to acquire knowledge and ameliorate governing processes. ${ }^{16}$

The risk-based governance, however, focuses on individuals as members of a given category of risk, determined by statistical distributions. Individual behaviours are

\footnotetext{
${ }^{15}$ For a complete and comparative account of the different policy approaches adopted in a number of $\mathrm{OECD}$ and non-member countries to cope with natural catastrophes and man-made disasters, see Monti (2008).

${ }^{16}$ O’Malley (2004).
} 
thereby governed in accordance with their association with a predetermined group. Thus, governance through risk implies actions taken in prevention of future risks identified through amoral assumptions and rational analyses. ${ }^{16}$

Both of these two governance approaches pose some difficulties to cope with large-scale disasters and they are not suitable for emerging catastrophic risks. The disciplinary governance approach, though it is more concerned with individual cases, will not avoid the occurrence of a risk, if the risk itself is not foreseeable. In this sense, tort law - if the main aim of which (as illustrated in the Law \& Economics literature) is to create a set of incentives to minimise the costs related with the occurrence of wrongful losses ${ }^{17}$ - might not work. In such circumstances, in fact, the etiological relation between the tortfeasor and the losses is unclear-or even more, there is no wrongdoer-and as a consequence, no prevention can be adopted (especially under a condition of ignorance). Hence, a disciplinary approach would not have the positive consequence of correcting deviant behaviours and eventually preventing future losses. On the other hand, the lack of a past record makes it, in theory, impossible to create an amoral stochastic rule, as generally adopted in the risk-based governance.

Similar considerations can be made if catastrophes are considered. In the case of extreme events, in fact, tort law is not necessarily the most effective policy tool. Even if the relation between human activity and abrupt climate change is proven, it might be hard to assess individual responsibilities and (as illustrated) optimal cost distribution and eventually prevention are not necessarily achieved.

Even more, due to the low frequency and the high impact of disasters, insurers tend not to provide coverage. As it is generally acknowledged, in fact, the so-called law of large numbers governs the insurance mechanism and drives the definition of price rates of insurance policies. ${ }^{18}$ To adopt such mechanisms (or, as social scientists would say, a "risk-based model of governance"), insurers need an insurable category of risk. Accordingly, risk has to be: (i) accidental, which means that losses cannot be intentionally provoked by the insured; (ii) determinable, which implies that insurers are able to calculate the premium rate as a function of its frequency and the severity of the damages; (iii) independent, in the sense that the losses should not be cumulative by affecting all of the insured at the same time. ${ }^{19}$

Extreme events have the characteristic of being hardly measurable (in terms of occurrences and losses) but highly cumulative. Accordingly, insurers have, for a long time, left uncovered the risks created by acts of war and nuclear, chemical, biological and radiation risks. ${ }^{20}$ These risks are often considered as uninsurable, because the catastrophe insurance market might not be able to assess (and thus absorb) the losses generated by such extreme occurrences.

${ }^{17}$ Calabresi (1970); Cooter and Ulen (2000).

${ }^{18}$ For a more precise explanation of the risk aversion aptitude and the role of insurers in absorbing the uncertainty of risk, through the pooling mechanism, see Shavell (2004) and Rejda (1998).

${ }^{19}$ Wagner (2007). The author also points out the softness of the concept of insurability that is actually not necessarily fully met.

${ }^{20}$ United States Government Accountability Office (2005). 


\section{From disasters to emerging catastrophic risks}

It appears that these characteristics are shared with different extreme events, including natural catastrophes, terrorist strikes, but also with other unexpected events - such as earthquakes, pandemic infections or the spread of a disease in a population exposed for years to toxic agents. ${ }^{21}$ Although important differences can be elicited among those scenarios, shared characteristics are evident, and common approaches might be identified.

The main features of uninsurability are indeed shared with emerging risk. Accordingly, in such particular peak-risk scenarios, there is

(a) an insufficient scope for risk pooling, because a large share of the population (within a given community) is affected simultaneously in the same way;

(b) uncertainty, if not ignorance, in assessing the nature and/or the consequences of risks;

(c) "adverse selection", 22 a problem, which might make insurance excessively expensive.

As clarified in the "Introduction" section, the main concern in emerging risks is not only related to low-probability/high-occurrence of losses, but is even more related to finding a proper way to tackle the ignorance that characterises the risk itself. As said, differently from other risks, emergent risks do not have a track record, which can be used to estimate likely probabilities and expected losses. Therefore, insurers cannot apply actuarial analysis to ascertain the probability of a given occurrence and estimate potential losses. Consequently they are unable to determine a price for such risks.

The only certainty is that the growing interconnection between people, markets and technological infrastructure might amplify every occurrence by turning it into a potential disaster. In some cases, losses are not even imaginable, although they will have a dramatic impact on the population, the state's resources and the global economy. In this sense the problem is often referred as "emerging systemic risks".

Of course, such a scenario does not provide the incentives to insurance companies to enter into such business, especially if governments tend to set up ad hoc compensation schemes in order to ensure a (partial) relief to victims. However, there is at least one good reason that rises above the other arguments: these kinds of occurrencesprecisely because we do not have the necessary knowledge - cannot be avoided. What is possible (in some cases), is to limit the damages - as is the case for earthquakes, by building in accordance with anti-seismic criteria or by applying the precautionary principle to new technologies.

${ }^{21}$ A key concept in toxicology is that toxicity is dose-dependent and time-related. Therefore, a substance might be non-toxic under a certain soil, but after long exposure, it might damage the exposed organism. This argument is crucial in the analysis of future expected losses generated by the unconscious subjection to chemical, physical or biological toxic agents affecting a vast majority of the population. For further details, see the U.S. governmental Agency for Toxic Substances and Disease Registry (ATSDR) www.atsdr.cdc.gov.

${ }^{22}$ Akerlof (1970). 
In this sense, emerging risks, because they are hardly predicted, are also hardly avoidable by risk-averse insurers. An abrupt climate change affecting different contiguous areas and ruining the agriculture industry in those regions might suddenly create unpredictable losses to insured farmers and thus to their insurers. Or the increase of specific syndromes due to a prolonged exposure to electromagnetic waves or to products with Genetically Modified Organisms (GMOs) of a large portion of the population will negatively impact the insurance system together and the national health system simultaneously.

\section{Solidarity and the private sector practices}

As scholars and international organisations have noted, even in countries in which the public action to compensate victims has been openly neglected after the occurrence of an extreme event, such as a climatic disaster, the state steps in to provide monetary relief to the victims. ${ }^{23}$ Accordingly, Tom Baker, by dealing with the solidarity principle in the US system, suggests that:

Although the US is supposed to be the land of the autonomous, competitive individual who rejects solidarity, in fact the enormous public and private insurance institutions built over the last 100 years represent a tremendous social commitment to de facto solidarity. The solidarities in many cases are narrower than they might be, and typically they are the collective result of relatively autonomous individuals acting in their self-interest rather than an expression of fraternal responsibility, but they are solidarities nonetheless. (emphasis added) ${ }^{24}$

However, the unpredictable amount of losses (not always absorbable using public resources only) leads a country to adopt solutions that call for a private sector intervention.

Even if individual prevention might not necessarily be a primary goal (as was explained in the previous section), it is true that individuals may adopt specific precautionary behaviour; and for the actions that an individual can take to minimise the impact of future losses, there is an insurance policy subscription. ${ }^{25}$

These behavioural and cultural approaches to insurance together with the impossibility to rely on stochastic analysis pose serious difficulties in developing a profitable market for emerging catastrophic events. Nevertheless, some responses from the business sector to cover peak-risks are currently in place, challenging the uninsurability argument. ${ }^{26}$ To the purpose of this work three different business practices are introduced here as they represent likely solutions the industry might

${ }^{23}$ Monti (2008).

${ }^{24}$ Baker (2002, p. 8).

${ }^{25}$ As explained by Browne and Hoyt (2000, pp. 291-306), sometimes individuals tend to not "insure themselves against possible natural disasters because they believe help will be available, from friends, family, the municipality, charities or state emergency programs".

${ }^{26}$ Accordingly Jaffee and Russell strongly question the very idea of uninsurability (Jaffee and Russell, 1997, note 19). 
develop to cover unavoidable emerging risks, namely the private sector might (i) strengthen the reinsurance net; (ii) spread the risk into the financial markets, through the securitisation mechanism; (iii) create a risk-pooling system.

Given that the characteristics of extreme events reveal that private insurance companies might not be able to provide proper coverage over a large scale with unexpected damages, all these practices aim at expanding the industry's capacity in absorbing losses.

Even more, such solutions - that can be combined in various ways - turn out to be particularly useful to tackle emerging systemic risks, characterised by a high level of unpredictability. ${ }^{27}$ In fact they help to reinforce the insurance-net, while further information about unexpected losses are gathered.

One of the most commonly used tools to expand the capacity of an insurer is the reinsurance mechanism, which in broad terms allows a reinsurer to pool the risks passed on by different primary insurers. As a consequence, an insurer can offer higher protection to policy-holders and exceed solvency requirements. In this sense, reinsurance companies will help to absorb large losses that otherwise could not be borne by an insurer.

Such techniques, however, transfer large losses to the reinsurers, which might determine - in the aftermath of a catastrophe - a substantial rise in the insurance premiums. As estimated by the International Monetary Fund (IMF), the cost of the 9/11 attacks to the United States was US\$40 billion; US\$35 billion were borne by reinsurance companies to pay off on underlying insurance contracts. ${ }^{28}$ Many reinsurers faced substantial losses (exceeding their reserves); Swiss Re declared a loss of US\$118 million. As a consequence, premium rates for covering terrorist risks increased substantially and in 2002, the U.S. insurance industry raised over US\$27 billion in new capital. ${ }^{29}$

In order to expand their capacity and, in particular, to cope with the losses generated by natural disasters, other tools are adopted, such as retrocession (a reinsurers' insurance) or, more specifically, catastrophe-related risks, which are now being sold by insurers and reinsurers to institutional investors in the form of catastrophe bonds, and other alternative risk-spreading mechanisms are enacted (like sidecar reinsurance). The latter two instruments will be briefly illustrated in the next paragraphs.

Another device to expand the industry's capacity is provided by the securitisation of risks (in particular to the purpose of this paper, through property-catastrophe risk financial instruments). After a series of natural disasters in the early 1990s (particularly after Hurricane Andrew), the reinsurance industry faced some unexpected difficulties and the price of reinsurance in the United States doubled, compared with the price from a few years earlier. Consequently, alternative financing tools were developed in order to create new financial instruments, to spread the risk and to permit the reinsurance industry to acquire new forms of financing. Catastrophe bonds

\footnotetext{
${ }^{27}$ For a complete account of the activity of the insurance industry in coping with natural disasters, see Monti (2009).

${ }^{28}$ As reported by Scott (2008) the Institute of Actuaries reported an average increase of 600-800 per cent of aviation policy rates; while property and casualty rates rose up to 50 per cent.

${ }^{29}$ Sisk (2002).
} 
(CAT-bonds) emerged ${ }^{30}$ to cover these new losses by transferring part of the risks to the capital markets. With such instruments, investors assume the risk of one (or more) low frequency/high severity event(s), such as a major earthquake. ${ }^{31}$ The mechanism triggering such financial instruments may vary and it could be more or less directly related to actual losses born by the insurer. ${ }^{32}$

The idea is that the flow of capital, normally circulating in stock markets, can easily absorb the risks related to such occurrences. Moreover, such financial instruments ensure a relatively high return and the fact that they are not related to economic conditions or to other financial instruments permits investors to achieve a portfolio diversification, by enhancing an alternative risk transfer mechanism.

CAT-bonds, which might be rated normally, only if multiple events are covered by the same instrument, ${ }^{33}$ are one of the most common forms of risk transfer. In recent times, another form known as sidecar reinsurance took place. With sidecars, a limited liability company takes a share (if not all) of the risk together with the reinsurer, in exchange for a share in the profit or loss the business generates. This has the effect of expanding the capacity of the reinsurer - who will be able to assume more risk - and will provide a significant profit to the investor in case the event does not occur.

However, although new forms of CAT-bonds have been developed, the use of such instruments still remains underutilised. ${ }^{34}$ Moreover, it would be necessary to expand the risk coverage by including other emerging risks; ${ }^{35}$ although, it is clear that the emerging risk (purely characterised by ignorance) by definition, cannot directly be the object of any financial instrument. In this case, it might only be a foreseeable derivative that is triggered by a reinsurer's default due to unexpected stress that is affecting, for instance, a specific risk line. This solution imposes an accurate modelisation, in order to spread the risk, for instance, of a pandemic contagion in a given region. ${ }^{36}$

${ }^{30}$ The first experimental transactions were completed in the mid-1990s by AIG, Hannover Re, St. Paul Re and United Services Automobile Association (USAA).

${ }^{31}$ For a complete account of such instruments, see International Association of Insurance Supervisors Report on the developments in (re)insurance securitisation (IAIS, 2009).

32 There are generally four trigger mechanisms, which determine four different CAT-bond structures, defined as indemnity, modelled loss, indexed to industry loss and parametric. The first two are triggered by the effective losses of the insurer (indemnity) or by a threshold of loss in accordance with given parameters; while the latter two are related to other parameters, like the whole industry's loss or even physical variables, like earthquake intensity (for further details see: www.air-worldwide.com).

${ }^{33}$ This is because a CAT-bond is rated in accordance with the probability that the negative event (e.g. hurricane or earthquake), and thus the related default, will occur; in this sense, many rating agencies are currently requiring multiple events in order to rate such securities.

${ }^{34}$ From 2002 to 2004, Swiss Re registered an increase of 50 per cent in the value of CAT-bonds. However, according to Grossi and Kunreuther (2005) only 3 per cent of the global reinsurance coverage was provided through such instruments.

${ }^{35}$ Lane (2002). See also Michel-Kerjan and Kunreuther (2005) for the possibility of creating derivatives linked to the occurrence of terrorist strikes.

${ }^{36}$ WEF (2009): A recent Report of the World Economic Forum noted that to accelerate the convergence of insurance with the capital markets sponsors and investors must both be encouraged to take advantages of the new opportunities represented by the securitisation of insurance product. In this sense a series of action involving the industry and policy-makers should be taken to make alternative risk transfers. 
402

Such hypotheses should be carefully considered in the light of the current financial crisis, in which excessive speculation and ignorance over derivatives contributed to the severity of the meltdown. Nowadays, a stronger reliance on stock markets to absorb emerging risks seems to be a less feasible solution.

Finally, the industry's capacity is most commonly expanded through the pooling mechanism: the risks held by insurance companies are pooled into a fund run by a consortium of insurers. ${ }^{37}$ More specifically, co-insurance or co-reinsurance groups can allow insurers and reinsurers to provide insurance or reinsurance for risks for which they might only offer insufficient cover in the absence of the pool. Moreover, pooling has the benefit for insurance and reinsurance undertakings to acquire experience of risks with which they are unfamiliar. Such arrangements might raise strong concerns from the antitrust authorities, as they might impose severe restrictions on competition; the possible friction between the private sector activity (to cope with emerging risks) and public action will be examined in the next sections of this work. Here, it is important to stress the importance of such solutions in dealing with emerging risks.

Large pools of similar risks (with low frequency) ensure a more stable and measurable mechanism that - also through information sharing - enables a more accurate estimation of future costs. Such pools are commonly used for different risk lines such as health, property, life insurance and catastrophes. ${ }^{38}$ For the most part, pooling peakrisks aims to collect individuals who are differently exposed to such risks. Therefore, to achieve its goal, pooling needs the participation of many individuals.

This is because lower risk individuals (those less exposed to a given occurrence) subsidise those with a higher risk. In other words, the pool must have a sufficient size to reflect a balanced cross-section of risks; alternatively, the premiums paid by individuals in a pool only composed of high risks will be high. It appears, as illustrated by Skogh and $\mathrm{Wu},{ }^{39}$ that pools are more efficient and effective to cover unforeseen risks, as a direct application of the Restated Diversification Theorem. ${ }^{40}$

It is also clear that in such circumstances, a problem of adverse selection becomes very relevant; yet, in a voluntary market, lower-risk individuals do not have the incentive to purchase a high premium. As will be illustrated in the subsequent sections, however, certain solutions might be in conflict with different policy goals, such as the promotion of a competitive market.

\section{Conflicting goals: a policy perspective}

For a number of reasons, either as a result of political or historical development or simply because no compensation schemes have been established for large-scale

\footnotetext{
${ }^{37}$ This latter mechanism is used also for the so-called Protection \& Indemnity (P\&I) Insurance of maritime insurers; it has became increasingly important after the environmental disaster, emanating from the shipwreck off the Cornish coast of the Torry Canyon, in March 1967.

${ }^{38}$ A noteworthy example is provided by the French GARET group for insurance and reinsurance of risks related to terrorist strikes.

${ }^{39}$ Skogh (2009).

${ }^{40}$ Skogh and $\mathrm{Wu}(2005)$.
} 
disasters, a public intervention might be required in case of cataclysm, not only to manage the crisis immediately, but also to (at least partially) compensate the losses generated by them. However, the huge amount of losses produced by such occurrences is often over and above public budgets. The international net provided by the insurance industry, through the practices enumerated in the section above, could help to better absorb such losses. To activate those practices, the creation of an insurance market has to be favoured, this being a prerequisite to any private intervention.

A coordinated and consistent system involving the participation of the public sector together with private actors requires the role of the state to be clearly defined, as a direct governmental intervention in compensating victims might stifle the creation of an insurance market. It is common to distinguish between ex ante and ex post interventions. In the latter case the government tends to directly compensate (at least in part) victims; whereas, ex ante actions generally imply the establishment of a structure able to absorb high losses (or a portion of them). Particularly, this latter solution sets up a planned system, whose aim is to favour private intervention. ${ }^{41}$

By adopting a broader policy perspective, it is possible to summarise such considerations in a trade-off rationale that imposes a balance between conflicting (at least in principle) objectives. Hence, if ex post solutions are dictated by the solidarity principle they might block a more effective distribution of losses, namely through a private market. On the other hand, ex ante solutions, when they imply direct legislative interventions, might be in contrast with competition law paradigms, as they entail contractual duties and/or concerted practices potentially harmful for the creation of a competitive market for first-party property insurance markets.

\section{Ex post approaches: direct public intervention vs. the correct set of incentives}

In the case of unforeseen (and unforeseeable) extreme events, public intervention to ensure victims' compensation is indeed what the population would expect from modern states. Moreover, it cannot be neglected that the population, which might hold excessive expectations of the role of central government in managing and compensating victims, perceives disasters differently. ${ }^{42}$ In this context, it was observed that during presidential election years in the United States, it was more likely that the government (in case an extreme event occurred) declared a state of emergency and provided financial help. ${ }^{43}$ This data suggests that governments (and, in general, politicians) are obviously aware that citizens expect an intervention from the state in the case of calamities. On the other hand, such interventions might generate a distortion in individuals' behaviour, encouraging them to be less prone to set up (if they are able to) effective precautions.

However, states can adopt different means to ensure compensation schemes for victims. For instance, in the United States, the Congress enacted the Terrorism Risk Insurance Act (TRIA) of 2002 (subsequently extended in 2005 and 2007) in order to

\footnotetext{
${ }^{41}$ For a complete account over the possible roles played by public and private sectors in compensating victims, see Van Boom and Faure (2007), Faure and Hartlief (2006).

${ }^{42}$ Monti and Chiaves (2006).

${ }^{43}$ Michel-Kerjan (2008).
} 
provide a quick answer to the limited availability of terrorism insurance after the attacks of 9/11. The TRIA 2002 set out a temporary programme providing public reinsurance for property/casualty and worker compensation industries. The main goal of this programme was to ensure enough time for the industry to collect data and elaborate a stable business practice to cope with the risk of terrorism. In other countries, ad hoc public funds are created to compensate victims for natural disasters. Certain countries (typically Germany, the Netherlands and Sweden) opt for a direct $e x$ post state intervention, by declaring a given occurrence as a catastrophic event and providing monetary compensation for victims.

Direct intervention from the public sector might lead to negative consequences in the long term: incentives for prevention are reduced as the government provides monetary aid. This is particularly true if ex post interventions are considered and the government provides direct monetary relief to victims. Subscribing to insurance might be considered unnecessary when states provide coverage. ${ }^{44}$ Accordingly, a survey made after the earthquake in Alaska (1964) reveals that, after the intervention of the U.S. government, which provided low-interest loans, the insured citizens declared that they would not have subscribed to any insurance if they had known that the state would have stepped in by providing direct financial intervention. ${ }^{45}$

Therefore, in a country such as Italy - where the recent earthquake in Abruzzo, devastating L'Aquila, dramatically reminded us that disasters still occur in geographical areas known to be prone to certain risks - a system for compensatory relief should also ensure a correct set of incentives fostering, where possible, precautionary individual activities, such as building houses in accordance with anti-seismic criteria and subscribing to a first-party property insurance. This leads to the consideration of ex ante policy approaches.

\section{Ex ante approaches: private sector response vs. competition law policies}

Ex ante solutions can be implemented in different ways but they generally involve a legislative intervention to foster the private sector's role in covering the populationfor instance, by granting fiscal benefits for first-party property insurance with a catastrophe policy extension. Moreover a price mechanism, in which precautionary activities are taken into account in order to calculate the final premium, might help to create an insurance market and to educate the population, by minimising the impact of natural disasters. ${ }^{46}$ Another typical ex ante solution often adopted is the compulsory catastrophe extension of first-party property insurance. This is the case in France, ${ }^{47}$

44 This is often considered a consequence of the Samaritan's dilemma (Buchanan, 1975), where helping poor people might provide wrong incentives to continue in behaviours that keep them in such a condition.

45 Dacy and Kunreuther (1969).

${ }^{46}$ A similar solution is currently adopted in HORA (Arbeitstitel Hochwasser Risiko Austria) in Austria and in ZÜRS (Zonierungssystem für Überschwemmung, Rückstau and Starkregen) in Germany, where there are openly available flood zoning systems, which aim to helping homeowners estimate the effective risk to which their lands are exposed, while insurers may use them for proper risk classification.

47 Art. L125-1 of the French Insurance Code, Code des Assurances, establishes that every insurance contract covering fire damages is automatically extended to those damages caused by natural catastrophes. 
which is often taken as a good example by many other countries, for example Belgium (where it has also been adopted as a mandatory scheme), ${ }^{48}$ Germany ${ }^{49}$ and Italy, where this option was proposed in two different occasions (see section "The Italian case").

Similar solutions can also be applied to emergent catastrophic risks especially if combined with a risk-pooling scheme that enables insurers to gather sufficient information on the unknown peak occurrences. A mandatory coverage, in application of the precautionary principle, can be potentially imagined in all those circumstances in which there is an effective threat of serious irreversible losses even if there is lack of full scientific certainty.

The approach just presented aims at ensuring coverage for (emergent) catastrophic occurrences, by enabling the application of risk-based techniques and the law of large numbers. The mandatory coverage and the pooling activity, in fact, would allow both the collection of a large sample of individuals, representing a heterogeneous group of risks, and the sharing of relevant information about risks with no previous record. Nevertheless, this solution has strong anticompetitive drawbacks. In fact, these arrangements constitute a tie-in clause, which imposes costumers to buy a product under the condition of purchasing a second distinct good. The practice is explicitly considered as an example of illegal arrangements under Art. 81 (1, e) of the EC Treaty. Even more, a tie-in arrangement when imposed by a firm with a dominant positioni.e. with a relevant market share - is banned under Art. 82(d) of the EC Treaty, as it constitutes an abuse of the dominant position. The latter prohibition reflects the concern that a firm benefiting from a dominant position might leverage it, through a tie-in contract, to gain monopolistic profits in a new market otherwise ruled by normal competitive pressures.

Moreover, mandatory extension generally entails at least other two features, which might negatively impact on competition: (i) prices for the compulsory coverage are normally fixed by legislative decision; (ii) a consortium or a pool of insurers or reinsurers is generally set up to expand the capacity of the industry. ${ }^{50}$

In this regard it is useful to briefly refer to the French system that complementarily displays both private and public intervention in which catastrophe extension of first-party property insurance plays a key role in the compensation scheme. According to this scheme, anybody purchasing first-party property insurance is required to buy a mandatory insurance to cover natural disasters. In France, property damages are often mandatory as provided by the Code des Assurances and-thanks also to the phenomenon of bancassurances - the coverage for property damage is a commodity easily purchased by bank account holders. As a result, according to the U.S.

Moreover, Art. L128-1 of the Code des Assurances provides for the same mandatory coverage when damages are caused by technological catastrophes.

48 The Law of 17 December 2005 (published in the Moniteur Belge on 11 October 2005, second edition) extended the first-party property insurance covering fire damages to natural disaster damages.

${ }^{49}$ For a view of the German approach to compulsory insurance scheme, see Schwarze and Wagner (2007).

${ }^{50}$ For a full account of the different anticompetitive outlaws touching the compulsory catastrophe extension of first-party property insurance, see Van den Bergh (2006). 
Government Accountability Office (GAO), the French government estimates that between 95 per cent and 98 per cent of the population benefits from comprehensive insurance. To cover natural catastrophe risk, insurers collect a government-determined 12 per cent premium surcharge from policy-holders. Insurers may then opt for reinsuring for natural catastrophes or purchase reinsurance from the private market or from the Caisse Centrale de Réassurance (CCR), a state company with the aim of providing reinsurance services for natural catastrophe risk. The state, first through the $\mathrm{CCR}$, then through public resources, thus offers unlimited reinsurance cover.

The anticompetitive effects generated by the breach of Art. 81 (1) of the EC Treaty can be compensated and an exemption from the ban can be granted under Art. 81 (3) of the EC Treaty, only if proportional benefits are achieved through the anticompetitive practice and the advantages are also proven to be beneficial for consumers. ${ }^{51}$ Such exemption can be granted on individual basis, by Member States' authorities and courts or by the EU Commission, or specific categories of agreements can be exempted through Block Exemption Regulations, which will be examined in depth in the sections "The Block Exemption Regulation rationale for pools" and "The definition of new risks and the BER".

It is clear that the French system is grounded on the wide diffusion of first-party property insurance. Even more, without an adequate diffusion of first-party property insurance, the mandatory extension on catastrophes would only leave the anticompetitive costs, without the required benefits. In fact, by leveraging the condition of first-party property insurance market, the compulsory coverage would not ensure any effective risk pooling and, further, the portion of the population more exposed to catastrophes risk, would not, necessarily, have been covered.

In addition to the mandatory extension, thus far only applied for catastrophic risk though it can be easily readapted to large variety of emergent risks, it appears that another aspect is noteworthy as it might have relevant anticompetitive consequences: the grouping or pooling practices.

As illustrated in the section "Solidarity and the private sector practices" to cope with emerging peak risks, a pooling activity (together with reinsurance and securitisation strategies) appears to be pivotal to expand the industry's capacity (in fact, they often pair the mandatory extension). Nevertheless, such practices can hide anticompetitive agreements designed to fix prices or define common terms and conditions as precisely banned under the above-mentioned Art. 81 (1). In addition, in such a circumstance - when the benefits of risk pooling will be investigated in the light of the EU provisions, as will be explained in the section "The Block Exemption Regulation rationale for pools" - a proportional efficiency-saving, determining a positive advantage for consumers, can compensate the anticompetitive effects. Risk pooling helps to collect data about unknown risks and it allows the composition of a sufficiently large sample of individuals differently exposed to risks. For these reasons, the advantages for emergent risks are particularly high and a regime of block exemptions is in place in the EU.

\footnotetext{
${ }^{51}$ No exemption can be granted in the case of abuse of dominant position, for example Art. 82 of the EC Treaty.
} 


\section{Competition law concerns and the definition of new risks}

From the above it appears that ex post and ex ante interventions, differently shaping the role of the state and of the public sector, might enter into conflict with other policy objectives, in particular with antitrust policies. These were the reasons why the solutions put forward in Italy were severely criticised by the Italian antitrust authority, Autorità Garante per la Concorrenza e il Mercato (AGCM). Even more, the suspicious attitude towards certain practices of antitrust policies can also be found in the European competition law provisions that, on the one hand, establish a favourable regime for pooling activities dealing with new risks, on the other hand, drastically limit the application of such regime.

\section{The Italian case}

According to the Italian insurance supervisory authority, the property of private citizens is generally not covered by any kind of natural catastrophe insurance. This lack of prevention - as insurance policies can be seen as a preventive device-has dramatically shown its relevance on a number of occasions (e.g. the L'Aquila earthquake). Given the need for reforming the current system, it is useful to recall here the past: failed attempts made in 1999 and 2003 to create a private compensatory system for catastrophic risks. In fact, as the two subsequent bills reveal a reformapproach made by trial and error, the analysis here conducted might outline some positive indications for a future, more consistent, reform in which emergent catastrophic risks are also considered.

Through a consultation procedure established by article 22 of Law no. 287 of 1990 (the Italian antitrust law), in $1999^{52}$ and in $2003^{53}$ the AGCM analysed two different proposals, both aiming at providing a compensation scheme for victims by pooling catastrophic risks and adopting a mandatory extension for catastrophes on first-party property insurances. During the first consultation, the AGCM raised a three-folded argument based on an antitrust analysis, which ultimately leads to a negative evaluation. The first concern was dealing with the unjustified involvement of the first-party insurance market. In fact, a tie-in effect was noted by the authority, in the sense that a duty imposed to jointly sell first-party insurance and catastrophes coverage would have transferred the concurrence restrictions (necessary to deal with natural disasters) to the first-party property insurance, in which such restrictions were not required. In this sense the experience of different countries, namely the United Kingdom, in which catastrophic risks are covered without imposing such a duty, was expressly considered. ${ }^{54}$ Finally, the AGCM clearly stated that the obligation imposing

52 AS168 AGCM.

${ }^{53}$ AS270 AGCM.

${ }^{54}$ Although in the United Kingdom insurance policies for natural disasters are not mandatory, the coverage is generally included in property damage insurance. The price varies in accordance with the risk exposure and in certain regions - it occurs in areas more prone to flooding - where it is more difficult to obtain flood coverage. Nevertheless, according to the GAO, the U.K. government estimates that 99 per cent of homeowners have coverage for natural disasters. A similar situation can be also observed in 
a mandatory extension for catastrophes on first-party property insurance was unnecessary on the grounds that first-party property insurance is not compulsory in Italy; ${ }^{55}$ thus, a mandatory linkage with a coverage for disasters would not have allowed the creation of a heterogeneous risk-pooling, nor coverage of the uninsured part of the population that was more exposed to risk. Accordingly, any loss resulting from such an anticompetitive arrangement would not have been compensated (and thus justified), as no benefits could reasonably be foreseen.

By rejecting the subsequent proposal, in 2003 the AGCM, the authority stressed again the ineffectiveness of this duty, if insurers, subjected to the compulsory extension, were not selected on the grounds of their risk exposure. Moreover, several concerns emerged about the determination of the prices, which, in the latter law-draft, were strictly bound to the risk exposure. This would have completely stifled any chance to have a competitive market for natural disaster insurance.

The AGCM finally raised another noteworthy issue, which will be examined in the subsequent sections. Natural catastrophes, as addressed by the law proposal, could not be considered new risks (or emerging risks, using the terminology adopted in this work) according to the European Regulation on Block Exemptions CE 358/2003. As a consequence, a per se exemption could not be granted, but a compensation among costs and benefits would have to be performed individually.

\section{The Block Exemption Regulation rationale for pools}

The last point leads us to further investigate one of the main, though often neglected, aspects of the EU competition policy regarding emerging catastrophic risks. Within the European Union, a specific Block Exemption Regulation (BER) is in force according to "the application of Article 81(3) of the Treaty to certain categories of agreements, decisions and concerted practices in the insurance sector", which is due to expire 31 March 2010, ${ }^{56}$ and which will be renewed with some modification for another seven years. ${ }^{57}$ This regulation aims at facilitating a number of practices that, subject to certain requirements, are deemed to compensate a priori anticompetitive effects.

Germany, where, however, it appears that few policy-holders choose to purchase the optional coverage for natural disasters and it may be difficult to obtain certain coverage (such as flood insurance, in areas where the risk occurrence is higher).

${ }^{55}$ First property insurance is compulsory only for mortgaged properties.

${ }^{56}$ Commission Regulation (EC) No 358/2003 (2003), OJ L 53, 28 February 2003.

${ }^{57}$ Regulation $358 / 2003$ currently includes four categories of insurance agreement, namely agreements for the exchange of statistical information for the calculation of risk, agreements establishing non-binding standard policy conditions for direct insurance, pool agreements for the joint coverage of certain risks, and agreements relating to specifications for security devices. The Commission has been reviewing the application of the current exemption and endorsed a public consultation, in order to understand whether (and till what extent) it is still necessary and justified a BER. The decision was to renew the BER for another seven years. Although, non-binding standard policy conditions and specifications for security devices were not anymore included in the BER, as they were not deemed to be sufficiently specific to the insurance sector to warrant automatic exemption. 
In fact, when a practice falls into the scope of the BER the European Commission automatically authorises insurers to calculate: average costs for specific risks, cooperation in studying the potential impact of external conditions on future claims, joint creation of optional standardised policy forms, joint data collection and distribution of profitability models, voluntary insurance and reinsurance groups, and various technical specifications. As a result, every firm participating in such a cooperative scheme can access the same data, which is necessary to better cope with emerging risks. Moreover, a common risk classification scheme, simultaneously applied by all the firms, can be employed to prevent adverse selection.

The new proposal, which is likely to come into force soon, renews BER for seven years, but with relevant changes for pools. Hence, the exemption for the exchange of information will only apply where information sharing is necessary to improve the knowledge of risks, making it easier for new insurers to enter the market, and ultimately benefiting consumers. Access to the data should be made available on reasonable and non-discriminatory terms, not just to insurers and new entrants to the market, but also to interested third parties, such as consumer groups and academics.

Even if, in general terms, the Commission considers that any institutionalised group of insurers is, by definition, restricting competition, the acknowledgement of specific benefits represents the rationale for a block exemption regime. Thus, a grouping practice is authorised when the market share of its members does not exceed a given threshold. Moreover, the Commission has specified that with some kinds of risks, insurers have to gather a sufficient amount of diversified risk. This is because it is recognised that insurers have to match the risk profile of their portfolios to the average for the totality of risks in the given class. In such circumstances, it acknowledged that a pooling activity does not necessarily produce anticompetitive results. ${ }^{58}$ Particularly, a pooling activity benefits from a total exemption, for three years, without any market share threshold when it is created exclusively to cover new risks.

In line with such an approach, the Commission showed a favourable attitude towards the P\&I Clubs, ${ }^{59}$ even if the Commission estimated that P\&I Clubs covered about 89 per cent of the world market for maritime contractual and third-party liability insurance. ${ }^{60}$ This decision acknowledged that the real level of claims incurred by the insurer has to be the same as the average level of claims of all insurers. However, such a result-which implies a certain amount of risks covered by the insurer - in low probability/high damages occurrences, can be achieved only through a pooling mechanism.

Further, in such circumstances, pooling might have positive outcomes on competition. These practices, as in all arrangements that enable reinsurance on a larger scale, are seen as contributing to the increasing levels of competition. In high-risk

${ }^{58}$ Report of the European Commission to the parliament of 12 May 1999 concerning the application of the Block Exemption Regulation 3932/92 (2003) OJ L 398, 31 December 1992, now emended by Block Exemption Regulation No 358/2003 (2003), OJ L 53, 28 February 2003; COM, 1999, 142 final of 12 May 1999, n. 32.

${ }^{59}$ Faure and Heine (1991).

${ }^{60}$ Commission Report (1999), COM, 1999, 142 final of 12 May 1999, n. 29, p. 13-14. 
410

areas, as for emerging risks, pools permit small insurance companies to participate in a market otherwise inaccessible.

Moreover, insurers with high market shares may generate sufficient internal statistics to be able to make reliable calculations. The creation of joint calculations (like tables and surveys) promotes competition because it is clear that insurers with small market shares will not be able to gather sufficient information. Without such practices, only a few, large insurers will be able to provide such a specific coverage.

Hence, by increasing the number of market participants and by providing help to small insurers, co-insurance does not necessarily stifle competition. On the other hand, pooling could also facilitate the purchase of reinsurance by increasing the industry's capacity. Similar considerations can be made on reinsurance pooling arrangements. ${ }^{61}$ If, thanks to pooling arrangements, markets become even more competitive, these arrangements are often paired with unnecessary restrictions and the consumers will not receive a fair share of the resulting benefits. ${ }^{62}$ The Italian proposal reflected such malpractice, which was also witnessed in certain arrangements in the nuclear insurance industry. ${ }^{63}$ This explains why the Commission fixed such a threshold and an even less rigid approach was adopted when practice was established for new risks or for other risks (such catastrophic events) that necessitated a pooling arrangement. ${ }^{64}$ The new proposal, however, will apply the exemption for not-new risks only to pools, on condition that the aggregate market share held by the participating insurers inside and outside the pool does not exceed 20 per cent of any relevant market in case of co-insurance. ${ }^{65}$ This represents a significant change from the previous regime, which only calculated market shares within the pool.

\section{The definition of new risks and the BER}

The analysis of the EU antitrust law shows, however, an aspect often too little considered, which is essential in determining the success of policy actions asking for a greater cooperation of the private sector: the definition of "new risk", which are, according to the current BER, those risks involving an "entirely new insurance product". 66 Although only those risks falling into this category will have the

\footnotetext{
${ }^{61}$ Havens and Theisen (1985).

${ }^{62}$ On this point, a detailed analysis of competition law and insurance, with particular attention to the Block Exemption Regulation number 3932/92 (then substituted by the BER 358/2003) is provided by Michael Faure (2002).

${ }^{63}$ Faure and Van den Bergh (1990).

${ }^{64}$ In this sense the Block Exemption in Recital 22 states:
}

This Regulation therefore grants an exemption to any such co-insurance or co-reinsurance group which has existed for more than three years, or which is not created in order to cover a new risk, on condition that the insurance products underwritten within the group by its members do not exceed the following thresholds: 25 per cent of the relevant market in the case of co-reinsurance groups, and 20 per cent in the case of co-insurance groups. The threshold for co-insurance groups is lower because the co-insurance pools may involve uniform policy conditions and commercial premiums.

${ }^{65}$ In the case of co-reinsurance the share is 25 per cent.

${ }^{66}$ Recital 20 Commission Regulation (EC) No 358/2003 (2003), OJ L 53, 28 February 2003. 
exemption for three years from the date of the first establishment of the group, regardless of the market share of that group, ${ }^{67}$ the latest Report ${ }^{68}$ of the European Commission on the functioning of the BER does not provide any significant clarification on the definition adopted. ${ }^{69}$

Nonetheless, in such a framework what constitutes a "new risk" becomes crucial, as the narrow classification adopted strongly limits the application of pooling arrangements for emergent risks. In fact, the BER generally considers as new risks only those risks not existing before. Thus, existing risks (even if not yet insured) fall outside the definition of new risks. Further, if the nature of a risk has dramatically changed over time (as the natural hazards determined by the climate change) it is expressly considered not new.

A new risk, in accordance with such a definition, requires an entirely new insurance product and cannot be covered by additions or modifications to an existing insurance product. Thus, Article 2 at paragraph 7 of Regulation number 358/2003 states: "New risks means risks which did not exist before, and for which insurance cover requires the development of an entirely new insurance product, not involving an extension, improvement or replacement of an existing insurance product".

As a consequence, new risks are those events for which the subscription capacity necessary to cover the risk (a) is not known in advance, and (b) is not composed of a mixture of new and already existing risks. Under this perspective it is even uncertain as to whether two or more groups could coexist in pooling this line of risk; in fact, if more than one pool exists, the risk appears to be no longer new.

Some of these issues have been recently raised through the public consultation process launched by the European Commission, in particular the definition of new risks appeared vague and unpractical even in the new proposal and the three year exemption period appeared to be too short. On this matter, the Association of British Insurers, among the others, noted that three years are not sufficient to gather the necessary amount of information to price new risks. ${ }^{70}$ It is clear, indeed, that given the ignorance issue intimately related with these occurrences, it is quite hard to imagine that such time lapse would fit all the varieties of emerging catastrophic risks. In this sense it appears to be an arbitrary choice not related to any specific scientific or business need.

With respect to the new risks definition, according to Federation of Risk Management Association (FERMA) new risks should include a variety of circumstances among which risks with increasing frequency and severity (e.g. terrorism, climate change, etc.). ${ }^{71}$

\footnotetext{
${ }^{67}$ Article 7(1). Id.

${ }^{68}$ See Report from the Commission to the European Parliament and the Council COM (2009) 138 final, 24 March 2009, footnote 11.

${ }^{69}$ Yet, groups created to cope with risk not deemed new should respect a market share threshold Article 7(2). Id.

${ }^{70}$ ABI (2009)

${ }^{71}$ FERMA (2009); a similar remark was made by the European Federation of Insurance Intermediaries (Bipar, 2009).
} 
412

The Commission appears to have partially accepted such remarks by amending the narrow definition previously adopted. The draft of the new BER, in fact, at Recital 17 states that the definition of "new risks" includes only risks that did not exist before "or, exceptionally, risks whose nature has, on the basis of an objective analysis, changed so materially that it is not possible to know in advance what subscription capacity is necessary in order to cover such a risk are included in the definition". ${ }^{72}$

Yet, under the light of the precautionary vs. over-prevention debate (section "Emerging catastrophic risks: dealing with large-scale, unpredictable events") even the definition provided in the new BER could be excessively constricted. It has to be clarified that if a risk is totally unknown, in fact, it might be preferred not to place any preventive measures, as well as any insurance coverage; however, if there is the likely possibility that some kind of occurrences will produce high damages, precautions should also be adopted by promoting the industry's intervention, though this circumstance does not appear to be included in the BER's taxonomy. In other words, the definition provided in the BER, paradoxically, covers only those risks not considered as coverable risks by the industry, as they do not have a reasonable expectation to occur or they are so unpredictable that they cannot be even imagined.

\section{Conclusion}

From the above considerations it appears that the emergent catastrophic risk line is, by definition, composed of a wide range of events, which have much to share with cataclysms or man-made disasters, as all these categories represent peak-risk occurrences. However, ignorance, consisting of a lack of past records, together with the reasonable probability of increasing occurrences and losses, appear to be the main features that distinguish emerging catastrophic (or systemic) risks from other types of disasters. Moreover, the precautionary principle sets the boundaries in which a preventive activity is preferred to inertia. It appears, in fact, that there are a number of threats of serious or irreversible damages, which are prone to increase in frequency and magnitude.

Even though a policy action is required, from the analysis conducted here it appears that emerging catastrophic risks pose relevant problems in terms of governance, as neither disciplinary nor risk-based governances may directly be applied to cope with emergent risks. Nonetheless, there are different business practices and policy actions that the insurance industry and national governments might adopt to govern such catastrophes.

Among these practices the most reliable are surely the ex ante actions, which involve the participation of the private sector, through the creation of a first-party property market, which compensates victims of emerging systemic risks. These solutions are, indeed, a direct application of the precautionary principle and can be conceived as a device to reduce the level of ignorance in order to perform rational estimations, upon which risk-based governance techniques can be built.

\footnotetext{
${ }^{72}$ Draft available at: http://ec.europa.eu/competition/consultations/2009_insurance.
} 
The attempt to apply this governance approach is normally performed by implementing a series of actions, among which the most relevant are the compulsory catastrophe extension of first-party property insurance and the pooling activity of insurers and reinsurers. These techniques serve the purpose of determining a statistical distribution by creating space for a private market. Hence, the pooling mechanism needs to collect enough individuals in order for it to be beneficial, and thus pools might be paired with provisions imposing mandatory extension. Both practices have to be carefully examined under the competition law principles, as they might hide anticompetitive behaviour, namely abuse of dominant position and cartel-like behaviours.

Yet the European antitrust policy, as it emerges from the analysis of the BER, appears not to be prone to recognise the importance of ensuring effective protection over these systemic threats. The narrow definition of "new risks", in fact (even if partially expanded in the new draft), dramatically limits the scope of the exemption regime if not correctly interpreted. A totally new and unpredictable risk-as suggested in BER - is, indeed, likely not to be covered at all by insurers. Even more, the new BER still grants exemptions for a lapse of time that appears to be not necessarily sufficient to gather information on unknown risks.

At this point it appears that such a definition of new risks is not in line with the precautionary principle as stated in the EC Treaty. The lack of flexibility is de facto posing relevant barriers not only to the creation of a market for emerging catastrophic risks, but also to the knowledge of systemic events that might seriously compromise human security and society. A more realistic antitrust policy aiming at promoting pooling for emergent systemic losses represents one of the first fundamental steps towards a consistent governance of systemic threats.

\section{References}

ABI (2009) Comments on the draft Commission Regulation (EC) on the Application of Article 81 (3) of the Treaty to Certain Categories of Agreements, Decisions and Concerted Practices in the Insurance Sector, London: Association of British Insurers.

Akerlof, G. (1970) 'The market for 'lemons': Qualitative uncertainty and the market mechanism', Quarterly Journal of Economics 84(3): 488-500.

Baker, T. (2002) Liability and insurance after September 11: Embracing risk meets the precautionary principle, University of Connecticut School of Law Working Paper $n^{\circ} 4$.

Baker, T. and Simon, J. (2002) Embracing Risk: The Changing Culture of Insurance and Responsibility, Chicago, IL: University of Chicago Press.

BIPAR (2009) Consultation on the Draft New Insurance Block Exemption Regulation, Brussels, Belgium: European Federation of Insurance Intermediaries.

Bordo, M., Eichengreen, B., Klingebiel, D., Martinez-Peria, M.S. and Rose, A.K. (2001) 'Is the crisis problem growing more severe?', Economic Policy 16(32): 53-82.

Browne, M.J. and Hoyt, R.E. (2000) 'The demand for flood insurance: Empirical evidence', Journal of Risk and Uncertainty 20(3): 291-306.

Buchanan, J. (1975) 'The Samaritan's Dilemma', in E. Phelps (ed.) Altruism, Morality and Economic Theory, New York: Russel Sage Foundation.

Calabresi, G. (1970) The Cost of Accidents: A Legal and Economic Analysis, New Haven, CT: Yale University Press.

Cooter, R. and Ulen, T. (2000) Law and Economics, Massachusetts: Addison-Wesley Reading.

Crichton, D. (2008) 'Role of insurance in reducing flood risk', The Geneva Papers on Risk and InsuranceIssues and Practice 33(1): 117-132. 
414

Dacy, D.C. and Kunreuther, H. (1969) The economics of natural disaster: implications for Federal Policy, New York: Free Press.

Fairgrieve, D. and Howells, G. (2007) 'Rethinking product liability: A missing element in the European Commission's third review of the European product liability directive', Modern Law Review 70(6): 962-978.

Faure, M. (2002) Insurance and competition law: Balancing the conflicts, Paper presented at the conference on Global Issues in Insurance Regulation, London, 17-18 April 2002.

M. Faure and T. Hartlief (eds.) (2006) Financial Compensation for Victims of Catastrophes: A Comparative Legal Approach, Tort and Insurance Law, Vol. 14, Morlenbach, Germany: Springer-Verlang.

Faure, M. and Heine, G. (1991) 'The insurance of fines: The case of oil pollution', The Geneva Papers on Risk and Insurance-Issues and Practice 16(1): 39-58.

Faure, M. and Skogh, G. (2003) The Economic Analysis of Environmental Policy and Law: An Introduction, Chelltenham, UK: Edward Elgar Publishers Ltd.

Faure, M. and Van den Bergh, R. (1990) 'Liability for nuclear accidents in Belgium from an interest group perspective', International Review of Law and Economics 10(3): 241-254.

FERMA (2009) 'Public Consultation on Review of the Competition Rules Applicable to Agreements in the Insurance Sector-Draft New Insurance BER 5.10.09', http://www.ferma.eu.

Grossi, P. and Kunreuther, H. (2005) Catastrophe Modeling: A New Approach to Managing Risk, Germany: Springer.

Havens, C.W. III and Theisen, R.M. (1985) 'The application of United States and EEC antitrust laws to reinsurance and insurance pooling arrangements', Antitrust Law Journal 54: 1299.

IAIS (2009) Developments in (Re)Insurance Securitisation, Global Reinsurance Market Report, Switzerland: Midyear Edition (August 2009).

Jaffee, D. and Russell, T. (1997) 'Catastrophe insurance, capital markets, and uninsurable risks', Journal of Risk and Insurance 64(2): 205-230.

M. Lane (ed.) (2002) Alternative Risk Strategies, London: Risk Books, Haymarket House.

Michel-Kerjan, E. (2008) Toward a new risk architecture: Welcome to risk management 2.0, Paper prepared for The Irrational Economist Conference, 4-5 December 2008.

Michel-Kerjan, E. and Kunreuther, H. (2005) 'Terrorism insurance 2005', Regulation Magazine, The CATO Institute, Washington DC.

Michel-Kerjan, E. and Kunreuther, H. (2008) 'Managing large-scale risks in a new era of catastrophes', Journal of Reinsurance 15(3): 1.

Monti, A. (2008) 'Policy approaches to the financial management of large-scale disasters', in $O E C D$, Policy Issues in Insurance $n^{\circ} 12$, Paris: OECD Publication.

Monti, A. (2009) 'Climate change and weather-related disasters: What role for insurance, reinsurance and financial sectors?' West-Northwest Journal of Environmental Law \& Policy, Combined Issue, 15(1): 151

Monti, A. and Chiaves, F. (2006) 'Italy', in M. Faure and T. Hartlief (eds.) Financial Compensation for Victims of Catastrophes-A Comparative Legal Approach, Vienna, Austria: Springer.

OECD (2003) Emerging Systemic Risks in the 21st Century, Paris: OECD Publication.

O'Malley, P. (2004) 'The government of risks', in S. Austin (ed.) The Blackwell Companion to Law and Society, Oxford: Blackwell Publishing, pp. 292-308.

Posner, R. (2004) Catastrophe: Risk and Response, Oxford: Oxford University Press.

Rejda, E.G. (1998) Principles of Risk Management and Insurance, Reading, MA: Addison-Wesley.

Schwarze, R. and Wagner, G.G. (2007) 'The political economy of natural disaster insurance: Lessons from the failure of a proposed compulsory insurance scheme in Germany', European Environment 17(6): 403-415.

Scott, S. and Wellons, P.A. (2008) International Finance: Transaction, Policy, and Regulation, New York: Foundation Press.

Shavell, S. (2004) Foundations of Economic Analysis of Law, Cambridge, MA: Harvard University Press.

Sisk, M. (2002) 'The reinsurance rush', U.S. Banker, August: 36.

Skipper, H.D. and Kwon, W.J. (2007) Risk Management and Insurance: Perspectives in a Global Economy, Oxford: Blackwell Publishing.

Skogh, G. (2009) A European pool for industrial accidents. A proposal based on the restated diversification theorem, Paper presented at the 13th Joint Seminar of the European Association of Law and Economics and The Geneva Association, Bocconi University, 11 May 2009. 
Skogh, G. and Wu, H. (2005) 'The diversification theorem restated: Risk-pooling without assignment of probabilities', Journal of Risk and Uncertainty 31(1): 35-51.

Taylor, S. (1999) 'The harmonisation of European product liability rules: French and English law', International \& Comparative Law Quarterly 48: 419-430.

United States Government Accountability Office (2005) Catastrophe Risk-U.S. and European Approaches to Insure Natural Catastrophe and Terrorism Risks, Report to the Chairman, Committee on Financial Services, House of Representatives.

W.H. Van Boom and M. Faure (eds.) (2007) Shift in Compensation between Private and Public Systems, Tort and Insurance Law Vol. 22, Morlenbach, Germany: Springer-Verlang.

Van den Bergh, R. (2006) 'Compulsory catastrophe extension of first party property insurance from a competition policy perspective', in M. Faure and T. Hartlief (eds.) Financial Compensation for Victims of Catastrophes: A Comparative Legal Approach, Tort and Insurance Law, Vol. 14, Morlenbach, Germany: Springer-Verlang.

Wagner, G. (2007) '(Un)insurability and the choice between market insurance and public compensation systems', in W.H. Van Boom and M. Faure (eds.) Shift in Compensation between Private and Public Systems, Tort and Insurance Law, Vol. 22, Morlenbach, Germany: Springer-Verlang.

Water Information System Europe (2008) 'A European Flood Action Programme', from http://ec.europa.eu/ environment/water/flood_risk/consult.htm, accessed 15 September 2009.

WEF (2009) Convergence of Insurance and Capital Markets, Switzerland: World Economic Forum Report.

\section{About the Author}

Dr Giuliano G. Castellano is Research Associate at the Ecole Polytechnique (Pôle de Recherche en Gestion) in Paris and Lecturer in "International Financial Markets Regulation" at the International University College of Turin (Italy). He currently practices law in Milan (Italy). He is specialised in comparative law, competition law, financial markets regulation and global economic governance. 